\title{
WILHELM CONRAD RÖNTGEN
}

\section{ANOS DA DESCOBERTA DOS RAIOS X}

\author{
WALTER OLESCHKO ARRUDA *
}

RESUMO - Cem anos após a descoberta dos raios X, é quase impossível conceber a prática médica diária sem a sua existência. Relata-se de forma sumária como foi esta descoberta e o seu notável descobridor: Wilhelm Conrad Röntgen.

PALAVRAS-CHAVE: raios X, radiologia, Röntgen.

\section{Wilhelm Conrad Röntgen:100 years of $\mathrm{X}$-rays discovery}

ABSTRACT - One hundred years after its discovery, one can hardly conceive the medical practice without the existence of $X$ rays. A brief account of $X$ rays discovery and about its notable discoverer is presented.

KEY WORDS: $X$ rays, radiology, Röntgen.

No dia 8 de novembro de 1895, Wilhelm Conrad Röntgen, então professor de física na Universidade de Würzburg, Bavária, Alemanha, descobre uma nova espécie de radiação produzida pela passagem de uma corrente elétrica por um tubo de vidro sob vácuo, e que possuia a singular qualidade de, embora invisível a olho nu, produzir fluorescência ao incidir sobre um papel impregnado por cianureto de bário e platina. Mais impressionante era a capacidade destes raios de atravessar corpos sólidos (madeira, papel, partes do corpo humano), com maior ou menor intensidade, dependendo da natureza do material. Em 28 de dezembro de 1895, seu trabalho "Über eine neue Art von Strahlen" (“Sobre uma nova espécie de raios") (Figs 1 e 2), de 10 páginas, foi submetido para publicação e descreve de forma sucinta e objetiva a sua descoberta.

Embora muitos tenham acreditado que $\mathrm{x}$ foi a letra empregada pelo seu significado matemático de "desconhecido", isto é improvável, uma vez que todo o texto original foi escrito com $X$ maiúsculo, inclusive no seu manuscrito. No texto, Röntgen afirma ter empregado esta letra somente para, de forma sucinta, dar uma denominação a essa nova forma de radiação.

No dia 1 de janeiro de 1896, Röntgen enviou cerca de 70 cartas, contendo separatas de seu trabalho e a foto da primeira radiografia humana, da mão de sua esposa (Fig 3), para os mais conhecidos físicos da Alemanha, Suíça, Áustria, Holanda, França, Inglaterra e Suécia. A febre dos raios $\mathrm{X}$ havia apenas começado.

Wilhelm Conrad Röntgen, filho único de um comerciante têxtil alemão e mãe holandesa, nasceu em Lennep (hoje chamada Remscheid), na Vestfália, em 27 de março de 1845. Ai ele viveu seus primeiros 3 anos, quando a família entāo mudou-se para Appeldoorn, Holanda, em 1848. Holandês, foi a primeira língua por ele aprendida, sendo falada sempre em casa durante toda a sua infância. Em agosto de 1862, ele separou-se dos pais para prosseguir seus estudos na escola técnica de Utrecht, Holanda. Durante este período ele aprenderia, dentre outras matérias, o inglês, francês, e o alemão, sua "língua paterna". Röntgen não foi o que se poderia chamar de aluno exemplar, e na máteria de física chegou a receber um conceito de "zeer slecht" (muito ruim). 


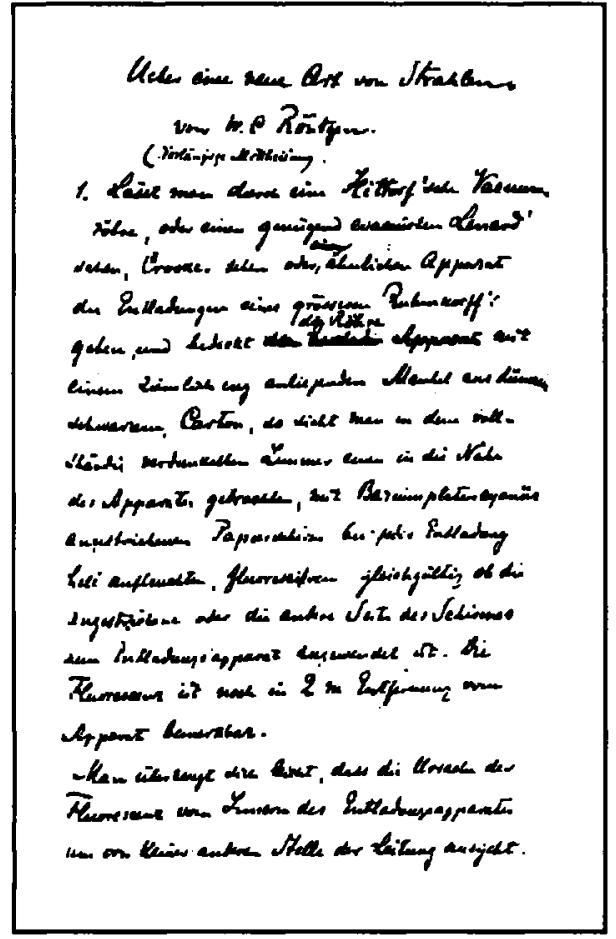

Fig 1. Primeira página do manuscrito submetido para publicafão no dia 28 de dezembro de 18952.

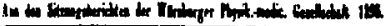

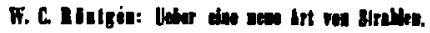

(Vorlinfige Xitubeileng.)

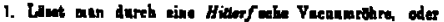

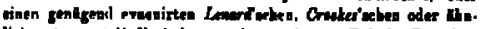

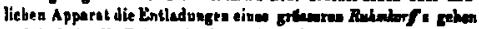

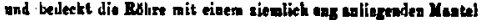

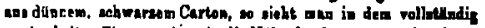

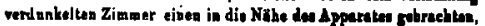

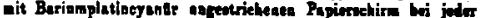

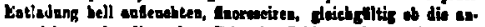

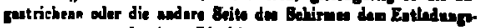

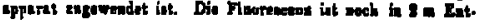
feraung rnm A pparat bourectbar.

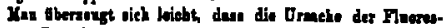

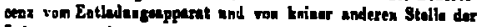
Leitur tacpht.

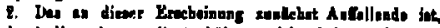

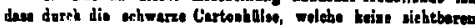
oder ultrevioletten Strablea Lee Sonnes- oder der elektriveben

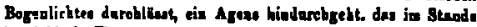

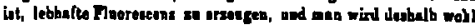

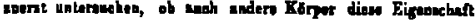
bustren.

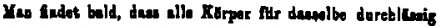

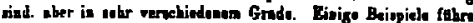
ich sn. Papiar int setr durchlëenig :1) hinter eibem oingebub-

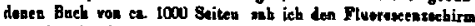
noch deatlich luneblen; dis Dructersobwirse bjetet kein mork-

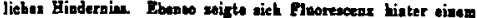

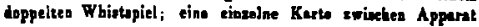

is

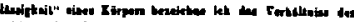

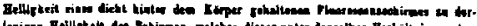

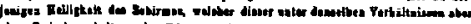

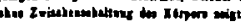

Fig 2. Primeira página do trabalho impresso e das separatas enviadas aos seus colegas por Röntgen em 1 de janeiro de $1896^{2}$.

Durante 1863 e 1864 ele preparou-se para os exames de ingresso na Universidade, tendo que se aperfeiçoar principalmente em línguas clássicas, grego e latim, um pré-requisito essencial na época para quem pretendesse iniciar urna formação universitária. Ele foi aprovado nas provas admissionais, mas foi matriculado em cárater provisório. Devido à insegurança e precárias perspectivas, no final de 1866 ele mudou-se para Zurique, Suíca, onde matriculou-se na Escola Politécnica, único local onde o conhecimento de latim, grego e de outras ma érias clássicas não constituía um pré-requisíto para uma prova de admissão (Abitur), o equivalente ao vestibular de nossos dias. Vinte anos mais tarde, um jovem de 16 anos,chamado Albert Einstein, iria tamberm matricular-se no Politécnico de Zurique por não precisar fazer a prova de admissăo para o ingresso.

No ano de sua chegada em Ztirique, 1866, ele conheceu Anna Bertha Ludwig, com quem casaria em 19 de janeiro de 1872. Um casamento feliz, sem filhos, que durou até a morte de Bertha em Munique, em 1919.

Em 1868, concluíram-se seus estudos e recebeu seu diploma de engenheiro mecânico. Este foi um ano crítico, pois seu professor em física, August Kundt, despertou e estimulou o interesse do jovem c inseguro Röntgen pela física experimental. De fato, em uma carta ao seu amigo Albert, escreve ele: "você ainda lembra, de que por seu intermédio eu tive o meu primeira contacto com Kundt, que me introduziu na fisica e dissipou as minhas incertezas acerca do meu futuro".

Em 1870, Röntgen foi convidado por seu mentor, August Kundt, para trabalhar na Universidade Würzburg como seu assistente. Novamente, as exigências das univerdades alemãs no tocante à sua formação escolar $\mathbf{e}$ ao conhecimento insuficiente de latim, língua utilizada na época em dissertaçőes acadêmicas, frustaram suas pretensð̃es de galgar uma carreira universitária e obter uma posição permanente. Em 1872, ele mudou-se para Estrasburgo, com Kundt. Entre 1873 e 1875, publicou 5 trabalhos experimentais com Franz Exner. Em 1874, tomou-se "Privatdozent" e, em 1876, Professor Extraordinário em Física na Universidade de Estrasburgo. 


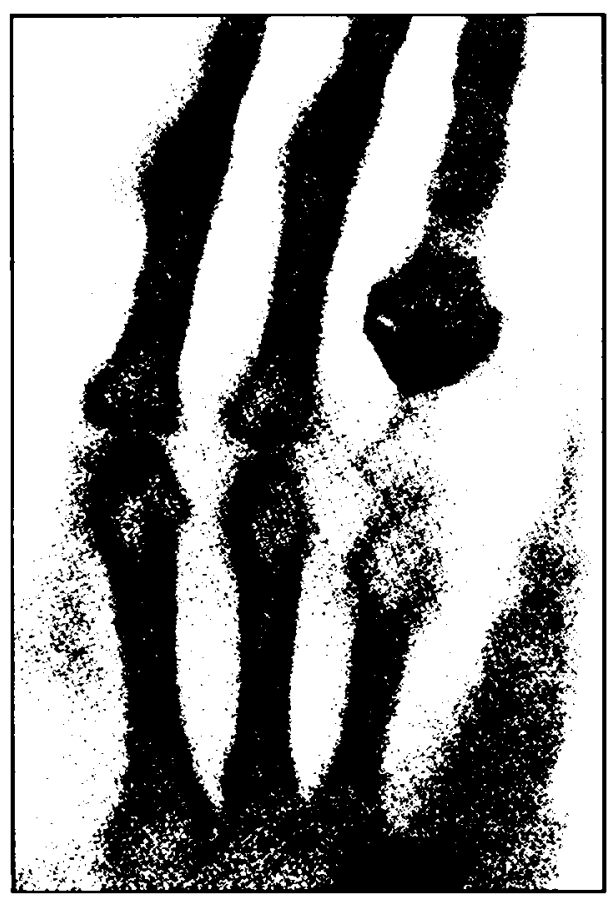

Fig 3. A primeira radiografia humana, da mão da Sra. Röntgen, tirada em 22 de dezembro de 18952.
Em 1879, ele assumiu a cadeira de Física na Universidade de Gießen e, durante esse ano, participou do seu primeiro e último congresso científico em sua vida! Em GieBen, no período de 8 anos, foram publicados 18 trabalhos, e a sua farna como pesquisador sério e já com certo renome comecou a difundir-se (Fig 4).

Ironicamente, em 1888 a Universidade JuliusMaximilian de Würzburg ofereceu o convite a Röntgen para assumir a Direção do Instituto de Física e a posição de Professor de Física, posição negada pelas autoridades bávaras alguns anos antes. Entre 1886 e 1895, Röntgen recusou outras ofertas de professor titular de física em universidades, como Jena, Utrecht e Freiburg. De fato, depois de sua ida a Würzburg em 1888, sua última mudança se daria para a Universidade de Munique, em 1900, onde permaneceu até sua morte, apesar de mais de uma vez ter sido convidado a assumir cargos de maior prestígio em Berlim.

Em 1894, um ano antes de sua descoberta, Röntgen foi nomeado reitor da Universidade de Würzburg. No seu discurso de posse mencionou as palavras do professor de filosofia P.A. Kircher, daquela Universidade: "A Natureza frequentemente permite a produção de milagres surpreendentes que se originam das mais ordinárias observaçōes, mas que são reconhecidas somente por aqueles imbuidos de sagacidade e pesquisa perspicaz, e que consultam a experiência, a professora de todas as coisas".

Em maio de 1894, Röntgen teve sua atenção chamada para um trabalho publicado por Phillip Lenard, físico em Berlim, sobre os raios catódicos, produzidos pela passagem de uma corrente elétrica em um tubo especialmente desenhado, onde vácuo era produzido. Ele iniciou então uma série de experimentos, tendo solicitado a construção e envio de diversos tipos de tubos de vidro a vácuo na firma Müller-Unkel, em Braunschweig, onde Lenard também solicitava a confecção da vidraçaria por ele desenhada. Em 1 de janeiro de 1894, Heinrich Hertz falecia em Berlim, e Lenard assumia a chefia do Instituto de Física em Berlim e outras funçðes acadêmicas na Universidade de Breslau. Com este acontecimento, forçosamente interrompeu seus experimentos nesta área. Mais tarde, Lenard protestaria por anos sobre a primazia na descoberta dos raios $\mathrm{X}$. Chegou a afirmar que se tratavam simplesmente de raios catódicos, já descritos por ele e não “uma nova espécie de raios". Seu importante nome e a simpatia de alguns físicos, também relutantes em reconhecer a importante descoberta de Röntgen, gerou uma polêmica que se estendeu por vários anos.

Em junho de 1894, Röntgen menciona ter feito observaçōes muito entusiasmadoras baseado nos experimentos de Lenard. Desde então e até a descoberta dos raios $\mathrm{X}$ em novembro de 1895, tem-se um período de absoluto silêncio e mistério, pois não há qualquer menção mais específica sobre o que ocorreu nesta época. Somente uma vez, ele menciona seu trabalho ao seu amigo, o zoblogo alemão Theodor Boveri, comentando "Eu descobri uma coisa muito interessante, mas não sei se as minhas observações estão corretas". Durante os últimos meses gelados de 1895 , a esposa de Röntgen escreveu mais de uma vez à sua família expressando preocupação com a saúde do seu marido, que quase não falava sobre seu trabalho, andava irritado, permanecia até altas horas da noite trancado no laboratório, onde inclusive fazia suas refeiçōes. O esforço não foi em văo. No final de dezembro, Röntgen publicava o resultado de tamanha dedicação e esforço.

Após a descoberta dos raios X, Röntgen concedeu somente uma entrevista mais detalhada a um jomalista inglês, H.J.W. Dam, da revista McClure's Magazine, em abril de 1896. Transcrevemos parcialmente a famosa entrevista. Dam ao perguntar como foi a história de sua descoberta, recebeu como resposta: 


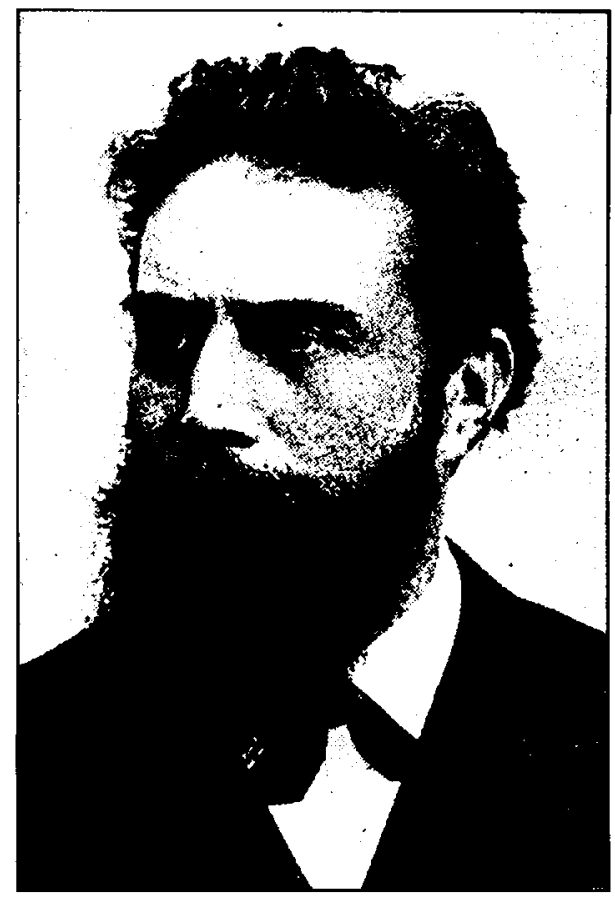

Fig 4. W.C. Röntgen, então com 40 anos $^{2}$.

e formulei uma série de experimentos com grande interesse, e estava determinado, assim que o tempo permitisse, a desenvolver um experimento próprio. Em outubro, dispus do tempo que eu precisava. Eu trabalhei por alguns dias, quando descobri algo de novo.

"Quando foi esta data?"

"Dia 8 de novembro."

"E como foi a descoberta?"

"Eu estava trabalhando com um tubo de Crooke, que revesti completamente com um cartão preto. Um papel embebido em cianureto de platina-bário foi colocado sobre a mesa. Quando deixei passar uma corrente através do tubo, notei com surpresa o surgimento de uma faixa preta sobre o papel

"E entāo?"

"Este fenômeno só poderia ocorrer, de forma usual, através da incidência de luz sobre o papel. Mas isto era impossível, pois o laboratório todo estava escurecido e o tubo coberto pelo papelão.

"O que o senhor então achou?"

"Eu não achei; eu pesquisei!"

A famosa publicação de Röntgen sobre "a nova espécie de rajos" foi traduzida rapidamente para outras línguas; no dia 23 de janeiro de 1896 surgiu na revista inglesa Nature, Inglaterra, no dia 8 de fevereiro na L'Eclairage Electrique, França, e em 14 de fevereiro na Science, nos Estados Unidos. Traduçōes em italiano, russo, polonês e japonês surgiram neste mesmo ano. Dois outros trabalhos sobre os raios $\mathrm{X}$ foram publicados em 9 de março de 1896 e em 10 de março de 1897, "Observaçōes Adicionais sobre as Propriedades dos Raios X", seria a terceira e última publicação, então apresentada na ata da Academia de Ciências Real da Prússia, em Berlim. Uma tradução em inglês da II parte de seu trabalho, em 1896, foi recentemente publicadas.

A estrondosa popularidade de Röntgen e de sua descoberta deveu-se antes à sua aparição precoce e imediata na mídia em todo o mundo, do que à sua publicação no meio científico. É curiosa a sucessão de eventos que levaram à uma tão rápida divulgação de uma descoberta científica no meio leigo. Franz Exner, foi um dos físicos e amigos de Röntgen que recebeu a descrição de seu experimento com 9 fotos de radiografias. Durante uma conversa num círculo de físicos vienenses reunidos no Hotel Reichshof, em Viena, Emst Lecher, de Praga, estava presente, pois tinha vindo passar as festas de final de ano com seu pai, redator do jornal 
"Presse". O resultado foi previsível. Lecher emprestou as fotos de Exner e mostrou-as a seu pai, que, surpreso com o que via, com argúcia percebeu a potencial importância da descoberta. Em 5 de janeiro de 1896 publicou a espetacular matéria entitulada "uma descoberta sensacional!". No 8 de janeiro surgia no New York Times a tradução do artigo publicado no jornal vienense "Presse", publicado três dias antes. Pela primeira vez, uma importante descoberta científica foi difundida em todo o mundo, em questão de dias, através do telégrafo.

No dia 12 de janeiro de 1896, Röntgen foi convidado a fazer uma demonstração em pessoa sobre a sua descoberta em Berlim, na presença do Imperador Guilherme II, Moltke e outras autoridades do governo, que rapidamente perceberam o alcance e utilidade não só médica mas também militar dos raios $\mathrm{X}$. Foi nessa ocasião condecorado com a Ordem da Cruz Real Prussiana, II. Classe.

Em 23 de janeiro de 1896, Röntgen fez a sua única apresentação pública, na reunião da Physikalischmedizínischen Gessellschaft, em Würzburg. Frente a uma audiência eufórica, radiografou a mão do renomado anatomista Rudolf Albert von Kölliker, com 77 anos, que propôs a denominaçăo "raios Röntgen" à nova descoberta, proposição ovacionada pela platéia em delírio. Já antes, em 12 de janeiro, Ludwig Boltzmann havia proposto o batismo dos novos raios como "raios Röntgen."

Durante esse ano, várias homenagens e condecorações foram conferidas, incluindo a medalha Rumford, da Royal Society London, e a Prix Lacaze da Academie des Sciences, de Paris. Por outro lado, como já mencionado, iniciou-se uma amarga polêmica em torno da forma como foram descobertos os raios $\mathrm{X}$. Não teria Röntgen simplesmente copiado os experimentos de Lenard e feito observações adicionais? Philiip Lenard, então em Kiel, mais de uma vez reclamaria para si a primazia da descoberta. Röntgen, após sua praticamente única entrevista publica com Dam, se calaria sobre as circunstâncias de sua descoberta até sua morte, não tocando neste assunto nem mesmo com seus mais íntimos amigos. Röntgen lamentou muitas vezes aos seus amigos, as intrigas e tentativas de difamação ocorridas na época, além de sentir-se extremamente importunado por uma tremenda publicidade, que o levava a tentar responder e recusar centenas de cartas e convites para palestras e demonstraçőes em diversas

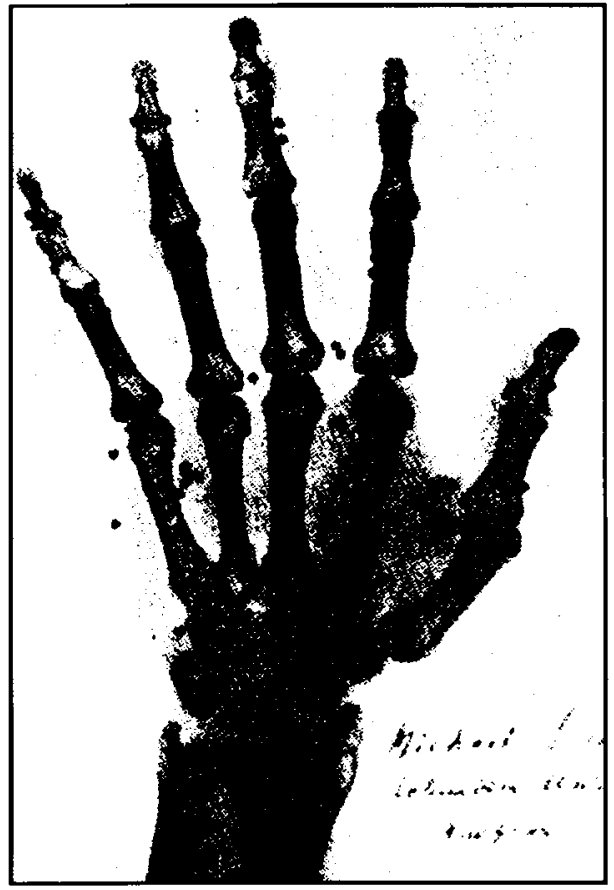

Fig 5. Radiografia da māo de um caçador, cuja arma disparou em sua mão, tirada por Micheal Pupin, professor de Eletromecânica da Columbia University, Nova Iorque, em fevereiro de $1896^{2}$. universidades na Europa e na América do Norte.

Em todo o mundo, vários pesquisadores acadêmicos e amadores passaram a reproduzir o experimento de Röntgen, e mais de 1000 relatos surgiram somente no ano de 1896. Rapidamente compreendeu-se a importante utilidade médica ao visualizarem-se corpos estranhos (Fig 5) e ossos com detalhe. Diversos modelos de tubos de raios $X$ rapidamente surgiram (Fig 6).

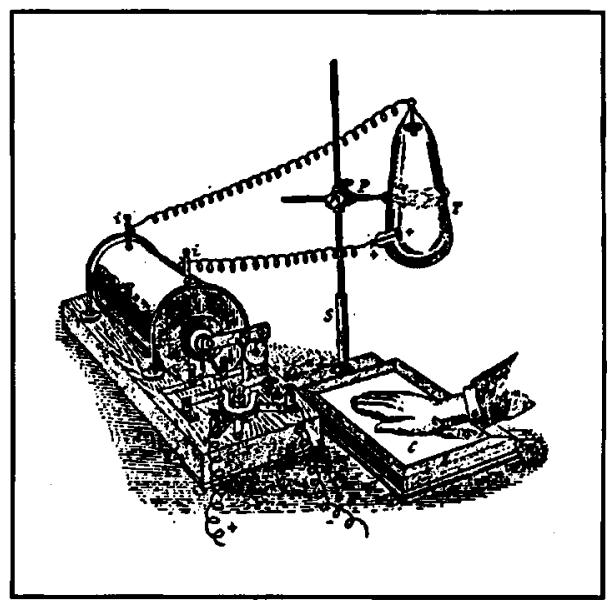

Fig 6. Um dos primeiros modelos de aparelho de raios $X$, este de $1897^{2}$. 


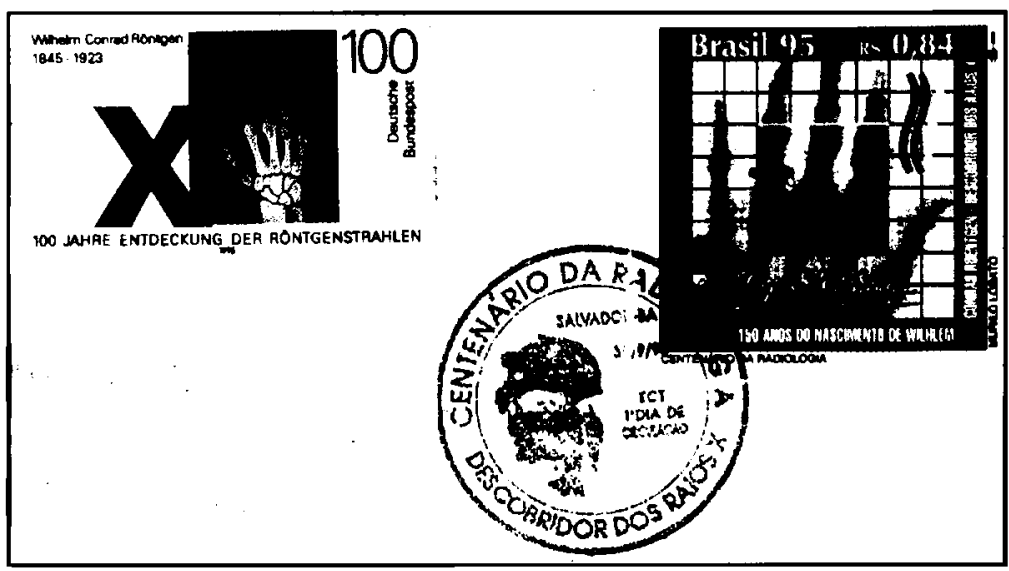

Fig 7. Selo comemorativo dos 100 anos da descoberta dos raios X emitido pelo Bundespost, Alemanha, em 1995, gentilmente cedido pelo Dr. Med. Michael Ruckdeschel. Selo comemorativo dos 150 anos do nascimento de W.C. Röntgen e dos 100 anos do descobrimento dos Raios X, primeiro dia de circulação (30.9.95), lançado durante o Congresso Brasileiro de Radiologia, em Salvador, $B A$.

Nos Estados Unidos, a primeira radiografia médica foi realizada em 3 de fevereiro de 1896,por Edwin Frost,um astrônomo. Foi a radiografia de uma fratura de Colles, no punho, de um rapaz atendido por seu irmão médico, Dr Gilman Dubois Frost ${ }^{2}$.

"O professor Röntgen provavelmente nāo ganhou nenhum dólar com sua descoberta." comentou Thomaz Alva Edison'. E ele estava correto. Após receber uma oferta do engenheiro Max Levy, da Allgemeinen ElektrizitätsGesellschaft (AEG), de patentear e explorar comercialmente a sua descoberta, Röntgen recusou o convite e respondeu que "meus achados e descobertas pertencem à comunidade, e não devem pertencer a um proprietário através de uma patente e licença." Edison, já então um renomado inventor, foi desafiado por William Randolph Hearst, em fevereiro de 1896, a produzir uma fotografia do cérebro com raios X. Após algumas semanas, ele abandonou frustado, o seu trabalho com o novo fenômeno. Contudo, não deixou de escrever alguns trabalhos sobre as propriedades fluorescentes do tungstato de cálcio, criou o termo fluoroscópio, e fundou a primeira companhia produtora de raios X, The Edison Decorative and Miniature Lamp Department of the General Electric Company. Tragicamente, Clarence Dally, assistente chefe de Edison, foi uma das primeiras vítimas da exposição excessiva aos raios X. "Queimaduras" que não cicatrizavam transformaram-se em lesðes malignas, que finalmente o levaram a 6bito em 1904. Röntgen nunca sofreu queimaduras por raios X, pois logo de início construiu uma cabine de estanho e chumbo, para não permitir a entrada de luz, mas também impenetrável aos raios, dentro da qual fazia seus experimentos, protegendo-o de sua exposição.

Em 1900, a Academia Real de Ciências da Suécia criou o prêmio Nobel. Foram solicitadas propostas dos diversos centros de pesquisa, para nomeação do primeiro prêmio Nobel de Física. De trinta propostas, inclusive a de Röntgen (que propôs o nome de Sir William Thomson, Lorde Kelvin), 12 nomes surgiram, incluindo Pieter Zeeman, Henri Becquerel, Philipp Lenard, J.J. Thomson e J.D. van der Waals. O comitê da Academia, presidido pelo brilhante físico-químico Svante Arrhenius, decidiu no início dividir o prêmio entre Röntgen, que havia recebido 12 propostas, e Lenard cujo nome recebeu somente uma proposta, formulada pelo professor Sylvanus Phillips Thompson, de Londres, considerado já uma autoridade entusiasta em raios catódicos e raios X, e fundador da British Roentgen Society, em 1897. Nada parecia mais justo, pois as observaçðes iniciais de Lenard haviam permitido a descoberta dos raios $\mathrm{X}$ por Röntgen. Como os primeiros prêmios de Química e Medicina foram conferidos somente a única pessoa, respectivamente o holandês Jacobus van't Hoff, pelas leis descobertas de dinâmica química e pressōes osmóticas, e o alemão Emil L. Behring, pela descoberta da soroterapia, após várias considerações, inclusive sobre a possível repercussão negativa em dividir-se o primeiro prêmio Nobel de Física, a Academia decidiu conferir o prêmio somente a uma pessoa: W.C. Röntgen, que o recebeu no dia 10 de dezembro de 1901 . O prêmio de 50.000 coroas suécas, foi doado por Röntgen à Universidade de Würzburg. Phillip Lenard receberia o seu prêmio Nobel de Física cinco anos depois. 
Somente em 1907, Röntgen publicaria o primeiro trabalho depois de 1897. Durante sua permanência em Munique, na Ludwig-Maximilians-Universität, somente mais 5 trabalhos seriam publicados, o último em 1921.

A comemoração de seu septuagésimo aniversário, a realização de uma grande festa em 27 de março de 1915, assim como a comemoração dos vinte anos da descoberta do raios X, foram prej'ıdicados pela I Guerra Mundial, que entāo assolava toda a Europa. Nāo obstante, colegas de todos os países incluindo J.J. Thompson, Charles Barkla e Emest Rutherford da Inglaterra, Madame Curie de Paris, H.A. Lorentz da Holanda, Abraham Michelson dos Estados Unidos, e naturalmente seus conterrâneos como Max Planck, Emil Warburg e Adolph von Bayer somaram-se a uma lista com o fim de formar uma fundação Röntgen. Apesar de nomes como Krupp e Siemens, ainda potentes economias na Época, participarem de tal empresa, somente 13.000 Marcos foram levantados, insuficientes para tal projeto. Neste ano, Röntgen ainda recebeu a Cruz de Ferro do Imperador Guilherme II, devido à grande contribuição dos raios $X$ na cirurgia militar. Este ano também foi marcado reveses como a morte de um de seus melhores amigos, Theodor Boveri, entao somente com 53 anos. Estes anos marcados pelas sombras de destruição e morte, demandaram sempre a sua cuidadosa atençāo à sua esposa, entāo agonizando lentamente de câncer e em uso de altas doses de morfina. Em 22 de abril de 1919 eles comemoraram os 80 anos de Bertha Röntgen que finalmente veio a falecer em 31 de outubro de insuficiência cardíaca e renal. Röntgen, agora só, tentaria "continuar vivendo, como eu imagino que minha esposa gostaria".

Em 10 de fevereiro de 1923, Röntgen faleceu vítima de câncer de intestino diagnosticado no início daquele ano, em Munique. Suas cinzas foram depositadas no túmulo de seus pais e de sua mulher, em Gieißen.

Röntgen nunca foi, apesar da importância de sua descoberta, uma verdadeira autoridade em Física, nem tampouco uma liderança ou fundador de um grupo de investigadores em Física. Talvez a sua glória e fama tenham advindo do fato de uma tāo importante descoberta dever-se a uma pessoa dedicada, séria e respeitada em seu meio, apesar de relativamente obscura. Röntgen encarnou o símbolo de excelência da pesquisa científica de seu tempo e sua descoberta foi indiscutivelmente o marco decisivo na História da Ciência ${ }^{2,3}$.

Uma obsessão pela precisão e pelo método científico e o desenvolvimento de seus próprios métodos e instrumentos necessários para sua pesquisa constituíram o leitmotiv do seu trabalho. Röntgen sempre soube que "a resignação deveria sempre impor-se a todo pesquisador". A causa desta resignação, Röntgen expôs no seu obituário a Friedrich Kohlrausch: " 0 pesquisador deve sempre contar com a possibilidade, e quase sempre com a certeza, de que seu trabalho, em um tempo relativamente curto, será sobrepujado por outros; que os seus métudos de trabalho serão aprimorados, e que os novos resultados obtidos serão mais precisos. Com isto gradualmente desaparecerá a lembrança desta pessoa e de seu trabalho." Apesar destas palavras, Röntgen deveria saber, no dia 8 de novembro de 1895, que a sua pessoa e a sua descoberta passariam a ocupar um lugar inesquecivel na História (Fig 7).

Agradecimento - A Carl Hanser Verlag, por gentilmente autorizar a reprodução das Figs 1 a 6, do livro de Fölsing ${ }^{2}$.

\section{REFERÊNCIAS}

1. Balwin N.Edison: inventing the century.New York: Hyperion, 1995.

2. Folsing A. Wilhelm Conrad Röntgen: Aufbruch ins Innere der Materie. München: Carl Hanser Verlag, 1995.

3. Glasser OWC. Roentgen and the discovery of the Roentgen rays. AJR 1995;165:1033-1041.

4. Goodman PC. The new light: discovery and introduction of the X-ray. AJR 1995;165:1041-1045.

5. Mould RF: Invited review: Röntgen and the discovery of X-rays. Br J Radiol 1995;68:1145-1176. 